\title{
PENGGAMBARAN AKAR PERMASALAHAN SENGKETA SUMBER DAYA AGRARIA PADA TANAH PERKEBUNAN BEKAS HAK GUNA USAHA
}

\author{
Oleh: Nurbaedah
}

\begin{abstract}
Abstrak
Penelitian ini dilatarbelakangi oleh adanya sengketa tanah perkebunan bekas hak guna usaha di Kecamatan Ngancar Kabupaten Kediri. Penelitian ini telah menemukan akar permasalahan penyebab sengketa sumberdaya agraria pada tanah perkebunan bekas hak guna usaha di Kecamatan Ngancar. Dengan menggunakan teknik wawancara secara mendalam menggunakan pedoman pertanyaan (guideline of interview) dengan Ketua Paguyuban Trisakti di tiga desa (Desa Babadan, Desa Sugihwaras dan Desa Sempu), tiga Kepala Desa (Desa Babadan, Desa Sugihwaras dan Desa Sempu), Direktur PT. Sumber Sari Petung Kediri, Kepaniteraan Perdata dan Pidana pada Pengadilan Negeri Kabupaten Kediri serta Kepala Kantor Badan Pertanahan Nasional Kabupaten Kediri. Hasil analisis dapat menemukan akar penyebab sengketa sumber daya agraria di perkebunan mantan hak atas tanah di Ngancar Kabupaten tumpang tindih perizinan dan perbedaan pandangan antara warga dan PT. Sumber Sari Petung, pembagian tanah antara warga dan perusahaan, pemenangan gugatan PT Sumber Sari Petung atas tanah seluas 250 ha, serta terjadinya kriminalisasi PT Sumber Sari Petung terhadap petani.
\end{abstract}

Kata Kunci: akar permasalahan, sengketa sumberdaya agraria

\begin{abstract}
This research is motivated by the existence of a dispute over land for explantation land use rights in Ngancar District, Kediri Regency. This research has found the root causes of disputes over agrarian resources on former cultivated land rights in Ngancar District. By using in-depth interview techniques using guideline of interviews with the Chairperson of the Trisakti Association in three villages (Babadan Village, Sugihwaras Village and Sempu Village), three Village Heads (Babadan Village, Sugihwaras Village and Sempu Village), Director of PT. Sumber Sari Petung Kediri, Civil and Criminal Registrar at Kediri District Court and Head of the Kediri Regency National Land Agency Office. The results of the analysis can find the root causes of disputes over agrarian resources in the former plantation land rights in Ngancar Regency, overlapping permits and differences in views between residents and PT. Sumber Sari Petung, the division of land between the residents and the company, the victory of PT Sumber Sari Petung's lawsuit over a 250 ha land, and the criminalization of PT Sumber Sari Petung against farmers.
\end{abstract}

Key Word: agricultural resource disputes, root causes 


\section{PENDAHULUAN}

Dalam pembangunan nasional, kepemilikan tanah dan pembaruan agraria menjadi hal penting untuk tercapainya kepastian, perlindungan hukum, dan keadilan serta kemakmuran bagi seluruh rakyat Indonesia. Tercantum dalam Tap MPR nomor IX tahun 2001 pasal 2 bahwa, pembaruan agraria mencakup suatu proses yang berkesinambungan berkenaan dengan penataan kembali dengan penguasaan, pemilikan, dan pemanfaatan Sumberdaya Agraria (perkebunan, kehutanan, pertambangan, dan perikanan). Salah satu sengketa sumberdaya agraria yang terjadi adalah kasus sengketa tanah perkebunan bekas Hak Guna Usaha di Kecamatan Ngancar Kabupaten Kediri sejak Tahun 1982. Sengketa ini terjadi antara warga Desa Sempu (Dusun Ringinsari dan Sumber Petung), Desa Babadan (Dusun Sanding), dan Desa Sugihwaras (Dusun Jambon) dengan PT. Sumbersari Petung atas tanah Negara seluas 6.342.760m².

Sengketa sumber daya agraria pada perkebunan bekas Hak Guna Usaha dimulai pada tahun 1982 pada masa Orde Baru, yang diprakarsai oleh tokohtokoh masyarakat dan dilanjutkan pada tahun 1998 yang diprakarsai oleh warga 3 desa yaitu Dusun Ringinsari dan Sumber Petung Desa Sempu, Dusun Sanding Desa Babadan dan Dusun Jambon Desa Sugihwaras melakukan gerakan untuk mengambil kembali hak atas tanahnya yang didasarkan dengan bukti Petok D dan Letter C Desa. Dengan semangat perjuangan tanpa henti, pada tahun 2000 telah mulai ada titik terang dalam perjuangan mempertahankan haknya.

Mengingat berakhirnya Hak Guna Usaha PT. Sumber Sari Petung tanggal 31 Desember 1999 sehingga terjadi klaim dari warga masyarakat Dusun Jambon, Desa Sugihwaras, Dusun Sanding Desa Babadan dan Dusun Sumberpetung, Ringinsari, Desa Sempu seluruhnya seluas \pm 372 ha dan terhadap klaim tersebut Bupati Kediri dengan suratnya tanggal 29 Nopember 1999 Nomor 890/2766/421.08/1999 menyatakan pada prinsipnya tidak keberatan diberikan perpanjangan Hak Guna Usaha kepada PT. Sumber Sari Petung atas tanah seluas 404,92 ha, sedangkan sisanya seluas 250 ha kembali jatuh pada negara dan selanjutnya akan diredistribusikan kepada para petani.

Berdasarkan Keputusan Nomor 66/HGU/BPN/2000 tentang Pemberian Hak Guna Usaha yang dikeluarkan oleh BPN RI, tanah perkebunan bekas Hak Guna Usaha seluas $6.342 .760 \mathrm{~m}^{2}$ ini dikelolah atau dimanfaatkan oleh kedua pihak tersebut. Tanah seluas $3.842 .760 \mathrm{~m}^{2}$ dikelolah oleh PT. Sumbersari Petung dan sisanya seluas $2.500 .000 \mathrm{~m}^{2}$ sebagai Land Reform yang dimanfaatkan oleh warga untuk kegiatan pertanian. PT. Sumbersari Petung menganggap bahwa perusahaan tersebut berhak atas tanah seluas 250 ha tersebut. Karena PT. Sumbersari Petung telah melakukan gugatan kepada BPN RI di Jakarta melalui Peradilan Tata Usaha Negara baik di tingkat banding maupun di tingkat Mahkamah Agung, dan PT. Sumber Sari Petung menjadi pihak yang dimenangkan. Akan tetapi, hingga saat ini putusan Mahkamah Agung tersebut belum pernah dilaksanakan oleh BPN RI menyangkut pembatalan Keputusan Nomor 66/HGU/BPN/2000 tentang Pemberian Hak Guna Usaha. Di sisi lain, warga 3 desa dalam mengerjakan tanah seluas 250 ha tersebut didasarkan atas SK Bupati Nomor 363 tahun 2001 dan SK Bupati ini belum pernah dijadikan objek sengketa atau dibatalkan. Kondisi inilah yang menimbulkan sengketa antara warga dengan PT. Sumbersari Petung.

Lahan merupakan asset penting untuk peningkatan kehidupan petani dan masyarakat, dengan sumberdaya yang dimiliki lebih kecil dibanding perusahaan. Hal ini sangat dipengaruhi oleh pengaturan kepemilikan lahan. Sedangkan dari 
sisi perusahaan, mereka tidak dapat memperoleh peningkatan keuntungan dan proses produksi yang ekonomis jika luasan lahan yang dapat dikelolah semakin besar. Adanya perbedaan ini yang menyebabkan adanya konflik sengketa atas suatu lahan perkebunan. Dalam menyelesaikan konflik terhadap kepentingan umum ini perlu diketahui permasalahannya, sehingga konflik dapat diatasi secara efisien dan efektif. Hal ini menumbuhkan upaya meneliti guna mengetahui secara obyektif akar permasalahan penyebab terjadinya sengketa sumber daya agraria pada tanah perkebunan Hak Guna Usaha di Kecamatan Ngancar Kabupaten Kediri. Dimana melalui akar masalah dapat diketahui permasalahan yang terjadi secara mendalam dan menyeluruh.

\section{METODOLOGI PENELITIAN \\ Metode Pengumpulan Data}

Jenis data yang digunakan adalah data primer dan sekunder. Pengumpulan data primer ini dilakukan dengan teknik wawancara tidak terstruktur menggunakan pedoman pertanyaan (guideline of interview) yang berlokasi di Desa Babadan, Desa Sugihwaras, dan Desa Sempu Kecamatan Ngancar Kabupaten Kediri, Jawa Timur yang ditunjukkan pada Gambar 1. Data yang didapat adalah tenteng rincian sumber dan kronologis permasalahan yang didapat dari beberapa narasumber.

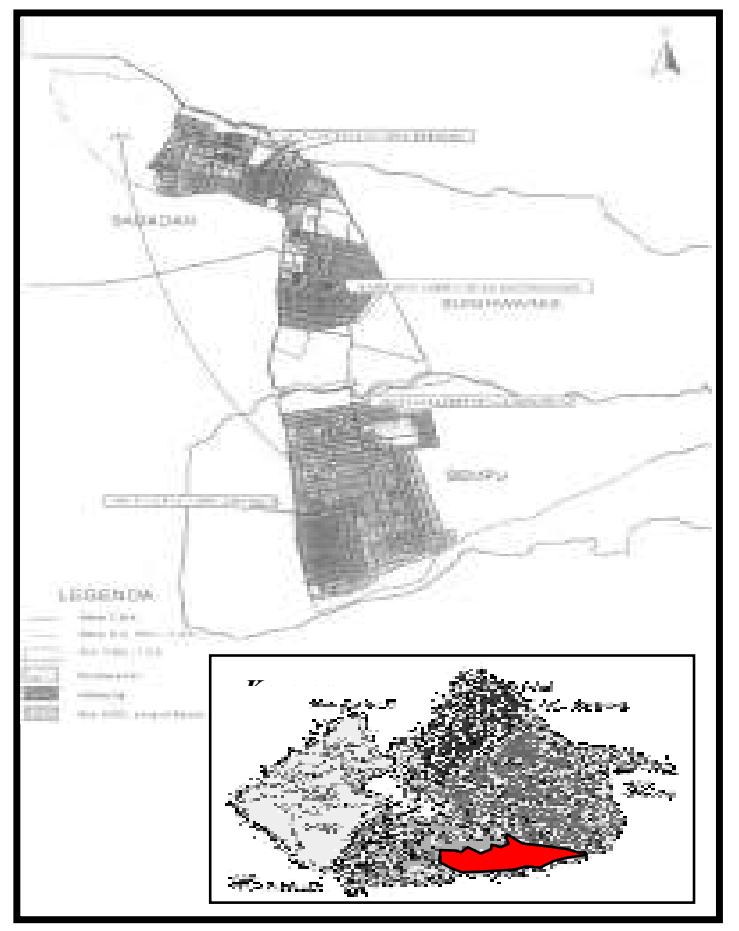

Gambar 1. Peta Lokasi Sengketa Tanah Perkebunan Bekas Hak Guna Usaha di Kecamatan Ngancar adalah:

Narasumber yang diwawancara secara mendalam (indepth interview)

1. Ketua Paguyuban Trisakti di tiga desa (Desa Babadan, Desa Sugihwaras dan Desa Sempu Kecamatan Ngancar Kabupaten Kediri, Jawa Timur);

2. Tiga Kepala Desa (Desa Babadan, Desa Sugihwaras dan Desa Sempu Kecamatan Ngancar Kabupaten Kediri, Jawa TImur); 
3. Direktur PT. Sumber Sari Petung Kediri,

4. Kepaniteraan Perdata dan Pidana di Pengadilan Negeri Kabupaten Kediri;

5. Kepala Kantor Badan Pertanahan Nasional Kabupaten Kediri.

Selain data primer, data sekunder diperoleh dari beberapa instansi pemerintah maupun organisasi masyarakat di Kecamatan Ngancar Kabupaten Kediri. Setelah pengumpulan data dilakukan, selanjutnya analisis dilakukan secara kualitatif dengan memaparkan data yang telah diperoleh.

\section{Metode Analisis Data}

Penelitian ini merupakan penelitian deskriptif kualitatif tentang sengketa sumber daya agraria pada tanah perkebunan bekas Hak Guna Usaha yang terletak di Desa Babadan, Desa Sugihwaras, dan Desa Sempu Kecamatan Ngancar Kabupaten Kediri. Analisis kualitatif perlu dilakukan dengan pendeskripsian secara detail dan mendalam melalui kalimat-kalimat. Metode analisis deskriptif kualitatif ini dilakukan dengan pemaparan data yang diperoleh dari penelitian baik data primer maupun data sekunder, kemudian dilakukan komparasi dengan teori dan studi terdahulu. Dalam pendeskripsian, penggambaran masalah dilakukan melalui penjabaran akar permasalahan. Dengan penjabaran akar permasalahan, dapat menjawab tujuan penelitian secara mendalam dan menyeluruh.

\section{HASIL DAN PEMBAHASAN}

Berdasarkan hasil wawancara terhadap beberapa nara sumber, maka didapatkan temuan berikut.

\section{Akar Permasalahan Sengketa Sumber Daya Agraria pada Tanah Bekas Perkebunan Hak Guna Usaha}

Menurut Samsianto (Ketua Paguyuban Tri Sakti, warga Desa Sempu), Terjadinya konflik ini diawali dengan adanya saling meyakini terhadap asal-usul tanah Hak Guna Usaha PT. Sumber Sari Petung karena awalnya masyarakat di sini sudah menguasai lahan sebelum adanya Hak Guna Usaha PT. Sumber Sari Petung. Namun pada tahun 1966 masyarakat di sini digusur, namun karena pada saat itu masa Pemerintahan Orde Baru sehingga masyarakat di sini tidak berani melawan dan pada Era Reformasi perjuangan itu dilanjutkan kembali. Pada saat reformasi, masyarakat mengusulkan kepada Bupati supaya 327 Hektar tanah Hak Guna Usaha PT. Sumber Sari Petung yang terletak di dua desa dapat kembali dikelola oleh masyarakat dengan dasar Leter C. Kemudian Bupati menyetujui 100 hektar saja, namun akhirnya Bupati menyetujui 250 hektar untuk diusulkan kepada Badan Pertanahan Nasional. Selanjutnya Bupati menyuruh mereka membuat panitia land reform dan setelah itu mereka membuat peraturan desa serta merumuskan kriteria penerima. Land reform menjadi sebuah kebijakan yang diambil oleh pemerintah yang dapat meningkatkan produktivitas petani, sehingga menciptakan peningkatan kesejahteraan petani.

Pada tahun 2000 BPN mengeluarkan SK BPN No. 66 tahun 2000 untuk menindaklanjuti persetujuan tersebut. Setelah itu Panitia land reform Kabupaten mengeluarkan titik koordinat sebagai tindak lanjut Surat Keputusan tersbut dan mengeluarkan buku Rincikan pada tahun 2000. Pada tahun 2001 Bupati Kediri mengeluarkan SK Bupati No. 363 tahun 2001 yang digunakan sebagai SK izin menggarap sebagai tindak lanjut SK BPN No. 66 tahun 2000. Sehingga masyarakat bisa menggarap lahan yang telah dibagi tersebut. Namun demikian 
antara tahun 2001-2004, BPN Kabupaten Kediri masih belum mengeluarkan sertifikat terhadap tanah-tanah tersebut meskipun BPN Pusat dan BPN Tingkat I telah memberikan Surat Perintah kepada BPN Kabupaten.

Mulai terjadi konflik yaitu pada tahun 2004 dimana PT Sumber Sari Petung melakukan gugatan kepada BPN Pusat di Pengadilan Tata Usaha Negara terhadap terbitnya SK BPN No. 66 tahun 2000, yang mengakibatkan konflik ini menjadi berkepanjangan. Hingga pada tahun 2008 Mahkamah Agung memenangkan gugatan PT Sumber Sari Petung tersebut. Putusan Mahkamah Agung tersebut menjadikan setiap musim panen cengkeh antara masyarakat dengan PT Sumber Sari Petung terjadi konflik.

Dari penjabaran permasalahan tersebut, akar permasalahan pada konflik sengketa Sumber Daya Agraria pada tanah bekas Hak Guna Usaha di Kecamatan Ngancar Kabupaten Kediri antara lain:

1. Tumpang tindih perizinan dan kepemilikian serta perbedaan anggapan, hal ini karena:

a. Secara historis, warga di 3 (tiga) desa berkeyakinan tanah obyek sengketa tersebut adalah milik leluhur yang seharusnya menjadi hak warga dan bukan menjadi hak PT. Sumber Sari Petung.

b. Hal itu dibuktikan dengan adanya bukti kepemilikan yaitu dokumen petok $\mathrm{D}$ dan Leter $\mathrm{C}$ desa

c. Dari pihak PT. Sumber Sari Petung juga mempunyai dasar penggunaan tanah tersebut

d. Hal itu dibuktikan dari adanya Hak Erpacht (Hak Guna Usaha) sebelum tahun 1960 dan akhirnya beralih atau dialihkan kepada PT. Sumber Sari Petung.

2. Pembagian tanah antara warga dan perusahaan, hal ini karena:

a. Warga mengusulkan kepada Bupati Suparyadi pada Tahun 1999 untuk hak penggunaan tanah sengketa agar dikembalikan kepada warga. Kemudian Bupati Kediri tersebut menyetujui tanah 250 ha yang dikelolah oleh masyarakat dan dikeluarkannya kebijakan land reform.

b. Hal ini dibuktikan dengan pada Tahun 2001 Bupati Kediri mengeluarkan SK Bupati No. 363 tahun 2001 yang digunakan sebagai SK izin menggarap tanah perkebunana bekas hak guna usaha oleh warga.

c. Bupati Kediri mengusulkan hak atas tanah seluas 250 ha kepada BPN untuk diatur kepemilikannya kepada warga dan dikabulkan oleh BPN

d. Hal ini dibuktikan dengan dikeluarkannnya SK BPN No. 66 Tahun 2000 sebagai bentuk pelegalan penggunaan tanah seluas 250 ha oleh warga, sehingga sisanya tanah seluas 397 ha menjadi hak perusahaan.

3. Pemenangan gugatan PT Sumber Sari Petung atas tanah seluas 250 ha, hal ini karena:

a. Gugatan dari PT Sumber Sari Petung kepada BPN pada Tahun 2004 di Pengadilan Tata Usahan Negara atas terbitnya SK BPN No. 66 Tahun 2000

b. Gugatan ini juga karena BPN Kabupaten Kediri masih belum mengeluarkan sertifikat terhadap tanah-tanah hak masyarakat meskipun BPN Pusat dan BPN Tingkat I telah memberikan Surat Perintah kepada BPN Kabupaten.

c. Gugatan ini juga disebabkan oleh pengembalian uang pembelian tanaman cengkeh di tanah 250 ha miliki perusahaan oleh warga senilai Rp. 200.000.000. 
4. Terjadi kriminalisasi PT Sumber Sari Petung terhadap petani, hal ini karena:

a. pengerahan ribuan aparat kepolisian untuk mengawal panen cengkeh oleh PT Sumber Sari Petung padahal cengkeh tersebut sudah dibeli warga, hal ini karena:

b. PT Sumber Sari Petung merasa memiliki ha katas tanah 250 ha karena Mahkamah Agung memenangkan gugatan PT Sumber Sari Petung pada Tahun 2008.

Berdasarkan konsep akar permasalahan, rinciap permasalahan di atas dapat divisualkan melalui flow chart maupun kerangka. Kerangka akar permasalahan dapat ditunjukkan pada Gambar 2.

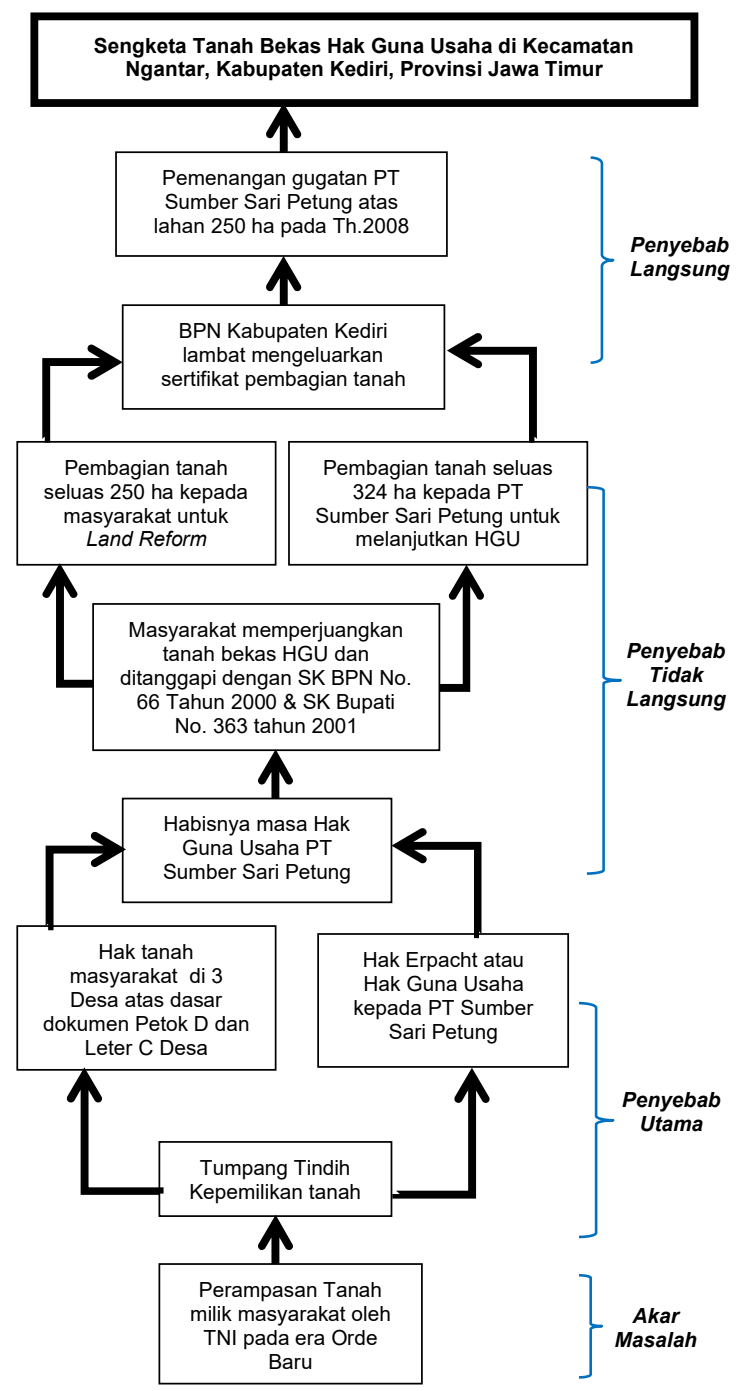

Gambar 2. Kerangka Akar Permasalahan Sengketa Tanah Perkebunan BekasHak Guna Usaha di Kecamatan Ngancar

Berdasarkan kerangka tersebut, dapat diketahui secara terperinci penyebab sengketa. Sesuai dengan konsep analisis akar permasalahan, analisis ini efektif untuk mendeteksi sumber penyebab masalah, sehingga langkah penyeledaian dapat dilakukan secara tepat. Terdapat empat penyebab terjadinya konflik dan enam penyebab dasarnya. Dengan menggunakan kerangka akar 
masalah ini, juga dapat diketahui permasalahan secara mendalam hingga pada inti awal permasalahan dan secara menyeluruh baik dari pihak masyarakat, PT Sumber Sari Petung, maupun pemerintah.

\section{KESIMPULAN}

Akar masalah sengketa sumber daya agraria yang terjadi antara warga dan PT. Sumber Sari Petung Ngancar Kediri Jawa Timur antara lain:

1. Akar masalah sengketa lahan ini adalah adanya perampasan tanah milik masyarakat oleh TNI pada era orde baru;

2. Penyebab utama permasalahan ini adalah adanya tumpang tindih kepemilikan tanah, yaitu : Hak Erpacht atau Hak Guna Usaha kepada PT Sumber Sari Petung; dan Hak tanah masyarakat di 3 Desa atas dasar dokumen Petok D dan Leter C Desa

3. Penyebab tidak langsung permasalahan ini adalah adanya Habisnya masa Hak Guna Usaha PT Sumber Sari Petung, kemudian Pembagian tanah seluas 250 ha kepada masyarakat untuk Land Reform dan Pembagian tanah seluas 324 ha kepada PT Sumber Sari Petung untuk melanjutkan.

4. Penyebab langsung permasalahan ini adalah BPN Kabupaten Kediri lambat mengeluarkan sertifikat pembagian tanah dan Pemenangan gugatan PT Sumber Sari Petung atas lahan 250 ha pada Tahun 2008.

\section{DAFTAR PUSTAKA}

Chomsah, A. 2004. Hukum Agraria Pertanahan Indonesia. Prestasi Pustaka.

Yelsang, F. 2013. Agricultural Land Use Conflict Between Landlords and Migrant Farmers in Ghana : An Examination of Issue Affecting Dagara Migrants in The Brong Ahafo Region. European Scientific Journal. Volume 9 No. 29 ISSN : 1857-7881 (print) e ISSN : 1857-7431.

Baum, C. 2011. The Benefits of Alternative Dispute Resolution in Common Interest Development Disputes. St. John's. Volume 84 no 3.

Harsono, A. 2008. Metode Analisis Akar Masalah dan Solusi. Jurnal Makara, Sosial Humaniora, Vol. 12, No. 2. Departemen IImu Komunikasi, FISIP, Universitas Indosesia.

A. Chaedar, A. 2002. Pokoknya Kualitatif. Jakarta: Pustaka Jaya.

Zikhali, P. 2008. Fast Track Land Reform and Agricultural Productivity in Zimbabwe. School of Business, Economics and Law University of Gothenburg, Working Paper in Economics No : 322.

Aerospace, B. 2011. Effective Root Cause Analysis and Corrective Action Process. Journal of Engineering Management and Competitiveness (JEMC) Universuty in Belgrade, Serbia. Vol : 1 No : $1 / 2$. 